\title{
"SUBSídIOS PARA INSTALAÇÃO DE UM SERVIÇO PARA ACIDENTADOS DO TRABALHO"
}

\author{
Maria José Schmidt*
}

RBEn/06

SCHMIDT, M.J. - Subsídios para instalação de um serviço para acidentados do trabalho. Rev. Bras. Enf.; Rio de Janeiro, 28 : 65-71, 1975.

$\mathrm{O}$ atendimento médico de acidentados do trabalho apresenta peculiaridades próprias que motivam a instalação de serviços específicos, visando não só a resolução rápida e eficaz dos casos clínicos ou cirúrgicos de emergência, mas também a continuidade do tratamento qualquer que seja a sua natureza e conseqüência.

Assim sendo, o hospital polivalente é a entidade adequada para a prestação de assistência aos acidentados. Quando se fala em hospital polivalente pretende-se focalizar não apenas a entidade que possui o maior número de especialidades, como aquela que, além de possuir unidades de internação, oferece também uma unidade de pacientes externos bem organizada.

A unidade de pacientes externos, quer no setor do ambulatório, quer no setor de emergência (pronto-socorro) é fundamental para o bom atendimento de acidentados. Enquanto o ambulatório visa a prevenção, investigação, diagnóstico e o tratamento de moléstias que não requeiram internação hospitalar, a emergência visa o socorro imediato a pessoas "cuja saúde é interrompida bruscamente, por um acidente, um agravamento súbito da doença, ou por outra causa qualquer, capaz de levar a um grave prejuízo na saúde, ou mesmo a morte, caso não seja atendida de emergência".

O planejamento cuidadoso de uma unidade de pacientes externos deve ser estabelecido diante dos objetivos do hospital e da clientela a ser atendida, sempre tendo em vista, a possibilidade de expansão.

O enfoque deste trabalho é o setor de emergência, destinado a atender principalmente acidentados do trabalho.

O dimensionamento de uma unidade para atendimento da infortunística trabalhista deve considerar o número de indústrias da região, o risco em potencial ligado a características do trabalho, o índice e o tipo de acidentes registrados, os recursos médicos existentes, a densidade demográfica, a proximidade de vias públicas movimentadas, a situação geográfica da comunidade a ser atendida e a facilidade de acesso por meio de condução coletiva.

A diversidade, freqüência e obrigatoriedade do tratamento, do início à alta,

* Enfermeira da Sub Secretaria de Seguros Sociais - INPS - SP. 
SCHMIDT, M.J. - Subsídios para instalação de um serviço para acidentados do trabalho. Rev. Bras. Enf.; Rio de Janeiro, 28 : 65-71, 1975.

nos casos de acidentes do trabalho de pequena e média gravidade, fazem com que o ambulatório seja o complemento indispensável do setor de emergência. Por sua vez, as demais dependências do hospital também são complementos indispensáveis para casos de acidentes graves, evitando a remoção do paciente, que muitas vezes torna fatal o acidente. Entretanto, este trabalho restringe-se apenas no setor de emergência, com apenas algumas referências a ambulatório e a hospital em geral, visto já serem temas de vários outros estudos, em publicações especializadas.

\section{I - SETOR DE EMERGÊNCIA}

1. Localização - Com relação ao prédio, o setor de emergência deve ocupar o andar térreo, sem escadas, com entrada independente e de fácil acesso para ambulâncias e outros veículos e ter interligação com o ambulatório e o hospital.

2. Área de serviços administrativos e circulação para o público - recepção e registro destinam-se a identificar o acidentado novo, registrar o seu atendimento, prestar informações aos familiares e outros e ainda controlar o seguimento do tratamento. Poderá ocupar uma parte da sala de espera (aproximadamente $8 \mathrm{~m}^{2}$ ), devendo ser separarada por balcão amplo (altura $1,10 \mathrm{~m}$. largura $0,40 \mathrm{~m}$.$) , com aproveitamento da$ parte interna com prateleiras para impressos, fichas de registro e outros, e comunicação com a secretaria arquivo.

A sala de espera ou salas de espera, cuja área física depende da amplitude do serviço, devem ser calculadas conforme a média diária de atendimento, incluindo pacientes e acompanhantes.

Os sanitários para o público, distintos para os dois sexos, devem estar localizados em área próxima e de fácil acesso, de preferência fora da sala de espera.
E importante também prever-se a instalação de bebedouros e telefones para o público.

Quanto ao mobiliário - cadeiras e bancos - devem ser confortáveis, de material de fácil limpeza e durabilidade (fórmica, plástico ou similar) e em quantidade suficiente para acomodar as pessoas cujo atendimento é previsto.

A circulação para o público, sempre que possível, deve ser isolacia da circulação de serviço, permitindo o trânsito livre de macas e cadeiras de roda. Junto à portaria deve haver um local apropriado (talvez um recuo de parede) para a guarda de macas e cadeiras de roda.

A dimensão das áreas de serviços administrativos e de circulação para o público poderá ser calculada na base de $2,5 \mathrm{~m}^{2}$ por paciente-dia. As paredes $\mathrm{e}$ pisos devem ser laváveis e de fácil desinfecção.

3. Área de serviços médicos e de enfermagem.

3.1 Sala de triagem e/ou consultório - Destinada ao exame rápido e diagnóstico provisório do acidentado.

Com dimensões aproximadas de $14, \mathrm{~m}^{2}$, paredes azulejadas até o teto, piso lavável com cantos arredondados, pia com tampo de mármore ou similar, oxigênio canalizado ou em torpedo, contendo: mesa ảe exame clínico; escadinha de dois degraus; carrinho de curativo devidamente equipado; armário com material e medicamentos de emergência; mesa secretária ou balcão para anotações; cadeiras.

3.2 Sala para exame e tratamento traumotológico - Para exame do aparelho músculo esquelético, tratamento confecção de aparelhos gessados ou goteiras.

Deverá ser localizada junto ao serviço de rádio-diagnóstico ou possuir um aparelho de RX portátil para uso exclusivo 
SCHMIDT, M.J. - Subsídios para instalação de um serviço para acidentados do trabalho. Rev. Bras. Enf.; Rio de Janeiro, 28 : 65-71, 1975.

da sala. Metragem aproximada $16 \mathrm{~m}^{2}$, pontos de luz para negatoscópio e serra elétrica, paredes azulejadas até o teto. piso lavável com cantos arredondados, pia própria com tampo de mármore ou similar e encanamento adequado para gesso. Equipada com: mesa ortopédica; escadinha de dois degraus; cadeiras; balcão ou mesa auxiliar; armário para material (ataduras gessadas, algodão, malha, crepe e outros); armário para instrumental; negatoscópio. Demais equipamentos para anestesia, uma vez que a mesma sala pode ser usada para reduções de fraturas e grandes engessamentos.

3.3 Sala de Tratamento de Enfermagem - Reservada aos curativos subseqüentes, administração de medicamentos (injeções e outros) oxigenioterapia (inalações etc.).

Com aproximadamente $16 \mathrm{~m}^{2}$, paredes azulejadas até o teto, piso lavável com cantos arredondados, pontos de luz nas paredes, pia com tampo de mármore ou similar, oxigênio canalizado ou em torpedo. Contendo: mesa de exame clínico; escadinha de cois degraus; cadeiras; mesa auxiliar ou balcão; suporte para braço; carrinho de curativo devidamente equipado (pacotes de curativo individual, retirada de pontos, gases e pacotes individualizados e de diversos tamanhos, desinfetantes, antisséticos e outros).

3.4 Sala de Pequena Cirurgia - Para a realização de pequenas e médias cirurgias que não requeiram internação hospitalar, porque o "atendimento de acidentados no centro cirúrgico, com sua possível contaminação, é primarismo condenável".

As dimensões recomendáveis são de $16 \mathrm{~m}^{2}$, paredes azulejadas até o teto, piso lavável com cantos arredondados, pontos de luz em todas as paredes, telas milimetradas nas janelas, oxigênio ca- nalizado ou em torpedo. Contendo: mesa cirurgica; escadinha de dois degraus; mesas auxiliares; mesa para anestesia; mocho; suporte para soro; suporte duplo para bacia; foco de lâmpada cialítica; "hamper" ou coletor de roupa usada; armário para medicamentos, instrumental e material (fios de sutura, drenos, sondas, anestésicos, e outros); aspirador de secreções; respirador artificial; equipo de anestesia.

Lavabo adequado, contíguo à sala de pequena cirurgia, com instalação hidráulica apropriada.

3.5 Salas de Repouso ou Recuperação para ambos os sexos - Destinadas à recuperação pós-anestésica das pequenas e médias cirurgias, secagem de aparelho gessado, repouso pós-traumático (mal estar físico ou psíquico, decorrente de acidente ou do tratamento), tratamento de emergência para os pacientes graves, enquanto aguardam internação hospitalar.

Recomenda-se localizá-las próximas à sala de pequena cirurgia e de tratamento de enfermagem, com sanitários anexos e dimensöes aproximadas de $14 \mathrm{~m}^{2}$. Contendo: dois leitos; mesinhas de cabeceira com comadre; compadre e cuba-rim; cadeiras suporte para soro; mesa de apoio e oxigênio canalizacio ou em torpedo.

$\mathrm{Na}$ área de serviços médicos e de enfermagem é imprescindível observar-se as exigências técnicas de construção hospitalar relativas à iluminação e ventilação.

\section{II — ÁREAS DE UTILIZAÇÃO CONJUNTA COM O AMBULATÓRIO}

O ambulatório constitui o traço de união entre o hospital propriamente dito, o setor de emergência e a comunidade.

1. Consultório 
SCHMIDT, M.J. - Subsídios para instalação de um serviço para acidentados do trabalho. Rev. Bras. Enf.; Rio de Janeiro, $28: 65-71,1975$.

Para exame do paciente por ocasião da alta, prosseguimento do tratamento ou consulta especializada, esse consultório poderá apresentar dimensões variáveis conforme a especialidade, podendo ser de 12 a $16 \mathrm{~m}^{2}$. No caso de ortopedia, o consultório deverá ter $16 \mathrm{~m}^{2}$ para permitir a observação da deambulação do doente.

Deve permitir a localização do seguinte material: mesa secretária; cadeiras; mesinha auxiliar; mesa para exame clínico; escadinha de dois degraus; caixa coletora para papéis usados; negatoscópio; aparelho de pressão arterial; estetoscópio bi-auricular; martelo para pesquisa de reflexos.

2. Radiodiagnóstico

Considerando o ônus das instalações desse serviço, o mesmo deve ser equipado para executar qualquer tipo de exame radiológico, tanto para os pacientes externos como para os internos, e possuir no mínimo, um aparelho de $\mathrm{R} \times$ portátel para os pacientes impossibilitados de locomoção.

A localização deve ser de fácil acesso para o atendimento de emergência e estar ligado ao sistema de circulação interna, sempre que possivel junto à sala de gesso, e com dimensões aproximadas de $3 \mathrm{~m}^{*}$ por exame radiológico realizado, e as seguintes divisōes: sala de espera; sala de exame com paredes blindadas e conjugada com sanitários (2) e vestiários (box de $2 \mathrm{~m}^{2}$ ); câmara escura com local para revelação; flxação e secagem de chapas radiográficas ou aparelho de revelação automática; secretaria e sala para diagnóstico.

3. Oftalmologia

Destinada principalmente, para o diagnóstico e tratamento de moléstias oculares e acidentes, inclusive retirada de corpo estranho.

O conjunto da oftalmologia compreende: consultório de ortótica e parime- tria, com dimensões aproximadas de $18 \mathrm{~m}^{2}$ (6 $\left.\times 3\right)$, com iluminação apropriada, equipo oftalmológico completo, inclusive com eletro-imã, armário com material e instrumental especializado; sala de tratamento ocular (curativo) com dimensões aproximadas de $9 \mathrm{~m}^{2}$, (cadeira própria para oftalmologia, carrinho de curativo ou mesa auxiliar com o material) medicamentos e instrumental adequado.

\section{Otorrinolaringologia}

Destinada especialmente para diagnóstico e tratamento ambulatorial e de emergência.

O conjunto de otorrinolaringologia compreende: sala de exame e tratamento com aproximadamente $12 \mathrm{~m}^{2}$, dotada de equipo otorrinolaringológico completo, negatoscópio, lâmpada flexível, armário com material e instrumental especializado, audiômetro; câmara acústica para audiometria com aproximadamente $3 \mathrm{~m}^{2}$.

\section{Odontologia}

Para diagnóstico e tratamento das afecções da boca, dentes e região maxllo-facial dos pacientes externos e internos Inclusive de emergência.

O conjunto odontológico compreende: sala de exame e tratamento com aproximadamente $12 \mathrm{~m}^{2}$, dotada de equipo odontológico completo, aparelho de $\mathbf{R ~ X}$ e com instalaçōes hidráulicas apropriadas; câmara escura para revelação de chapas radiográficas.

\section{Neurologla}

Para diagnóstico e tratamento das afeç̧ões orgânícas do sistema nervoso e sequelas de acidentes.

O conjunto de neurologia compreende o consultório e a sala do exame eletroencefalográfico.

7. Fisioterapia

Para tratamento fisioterápico por meio de ginástica corretiva, cinesiote- 
SCHMDT, M.J. - Subsídios para instalaçăo de um serviço para acidentados do trabalho. Rev. Bras. Enf.; Rio de Janeiro, $28: 65-71,1975$.

rapia, eletroterapia, hidroterapia, mecanoterapia, massoterapia, fisioterapia desportiva e técnicas espaciais de reeducação muscular para recuperação funcional compatível com as limitações.

A localização deste serviço deverá ser no andar térreo, sem sacadas, com entrada independente para pacientes externos e entrada privativa para internados. As dimensões dos diversos setores variam de autor para autor, contudo prevalece, quanto a área total, um cálculo de no mínimo $3 \mathrm{~m}^{2}$ por paciente dia.

O conjunto da fisioterapia compreende:

7.1 Sala de espera e recepção do paciente, conjugada com a secretaria.

7.2 Secretaria e arquivos morto e circulante.

7.3 Consultório para o fisiatra ou fisioterapêuta.

De preferência com $16 \mathrm{~m}^{2}$ (para possibilitar a observação da deambulação do paciente) e provido de: mesa secretária; mesa de exame clínico; escadinha de dois degraus; mesa auxiliar; negatoscópio.

\subsection{Eletroterapia}

Um box de aproximadamente $5 \mathrm{~m}^{2}$ $(2 \times 2,5)$ com ponto de luz sempre a um metro do piso e fios embutidos, paredes de material Isolante (celotex ou similar) para cada aparelho de: ultra-violeta; infra-vermelho; ondas-curtas; ultrasom; corrente galvânica e farádica; forno de Bier (cada aparelho deverá ter descarga elétrica (fio-terra) para evitar curto circuito).

\subsection{Hidroterapla}

As dimensões variam conforme o tipo e o tamanho dos aparelhos. Em geral o turbilhão, que é o mais usado, ocupa uma área de aproximadamente $9 \mathrm{~m}^{2} \mathrm{e}$ o banho de parafina $6 \mathrm{~m}^{2}$. O piso deve ser lavável e seguro (cerâmica ou simi- lar) e as paredes azulejadas até o teto. Os vestiários são complementos indispensáveis na hidroterapia.

\subsection{Mecano e cinésioterapia}

Sala de tração com mesa própria e aparelho de tração cervical e lombar, com aproximadamente $12 \mathrm{~m}^{2}$.

Ginásio com espaço suficiente para a circulação dos técnicos e pacientes e permitir a instalação dos seguintes aparelhos: colchonete para exercício ( $2 \times 2,5)$; barra de Ling; escada; rampa; paralela; andadeira; roda de ombro; bota de Delorne; bicicleta estacionária; polia para membros inferiores e superiores. A dimensão aproximada será de $40 \mathrm{~m}^{2}$, sendo que o teto deverá ser provido de trilhos para cortinas falicitando a divisão em espaços menores.

\subsection{Sala de avaliações}

Para avaliação da incapacidade remanescente. Dimensões aproximadas de $16 \mathrm{~m}^{2}$, contendo, além de mobiliário próprio para consultório (acima descrito) os seguintes aparelhos: goniômetros; dinamômetros; termômetros; esfigmomanômetros; corrente galvânica e larádica para teste.

Os vestiários para médicos, fisioterapêtas e pessoal auxiliar poderão ser exclusivos da fisioterapia ou em conjunto com o ambulatório ou ainda com o hospital.

\section{III - AREA DE UTILIZAÇA CONJUNTA COM O HOSPITAL}

\section{Centro de material e esterilização}

O setor de emergência e o ambulatório poderão manter apenas um arsenal de material e instrumental esterilizado para uso diuturno.

2. Farmácia ou Drogaria

Aqui também, ambos poderão manter 
SCHMIDT, M.J. - Subsídios para instalação de um serviço para acidentados do trabalho. Rev. Bras. Enf.; Rio de Janeiro, $28: 65-71,1975$.

um estoque de medicamentos de urgência e outros mais usados para poder atender à demanda semanal ou quinzenal.

\section{Laboratório}

A localização do laboratório deverá permitir o fácil acesso para pacientes externos e ter ligação direta com a circulação interna a fim de receber ou colher o material para exame e entregar os resultados.

\section{Banco de Sangue}

Desde que atenda com presteza os pedidos feitos e as exigências técnicas de instalação, sua localização não tem maior significado.

\section{Lavanderia}

O setor de emergência e o ambulatório poderão manter apenas o armáriorouparia para roupas limpas e a sala de utilidades para roupas usadas.

\section{Almoxarifado}

Poderá ser mantido apenas um estoque de material para atender as necessidades semanais ou quinzenais, tanto do setor de emergência como do ambulatório.

7. Serviço de Arquivo Médico e Estatística (SAME)

Dependendo da organização do hospital e da localização do SAME o mesmo poderá controlar os prontuários médicos do setor de emergência, inclusive de acidentados do trabalho.

\section{Contabilidade}

Nada obsta que o setor de contas nosocomiais prepare também as contas ambulatoriais e do setor de emergência, o importante é ter pessoal preparado para fazer as contas de acidentados do trabalho devido às peculiaridades próprias.

\section{Conclusão}

"O homem sadio é um bem que cumpre preservar e aquilo que se dispende para a preservação da saúde do indivíduo representa um lucro. $O$ homem sadio representa trabalho e quem fala em trabalho fala em aumento do produto nacional bruto, representado em bens de consumo produzido"(*) Este conceito aplica-se bem para a infortunistica trabalhista, porque, do ponto de vista econômico, cada acidentado representa para o país um tríplice ônus: assistência médica (médico-cirúrgica, farmacêutica, odontológica, e reabilitação profissional); benefícios pecuniários (auxílio doença acidentário, auxílio acidente, pecúlio, pensões e aposentadoria), paralização da mão de obra. Isto tudo, sem contarmos com o valor do indivíduo como pessoa humana na sua família e na comunidade.

Sendo assim, quanto mais bem organizados forem os serviços de atendimento de acidentados, melhor será o seu padrão de assistência, reduzindo o tempo de afastamento do trabalho e o ônus dos benefícios, e conseqüentemente contribuirá para o aumento da economia nacional.

Cabe às enfermeiras uma grande parcela de responsabilidade na instalação: organização e funcionamento dos serviços de acidentados do trabalho, devendo as mesmas, além de supervisão do pessoal de enfermagem, do ambulatório e do setor de emergência, participar também das equipes de planejamento.

Este trabalho não tem a pretensão de ser completo, apenas oferece alguns subsídios para que as enfermeiras possam colaborar efetivamente na organização do setor de emergência, procurando racionalizar o trabalho aproveitando os recursos existentes na entidade.

* Antigo conceito da medicina utilitária dos romanos, aplicada pela Carta do Chile em 1942. 
SCHMIDT, M.J. - Subsídios para instalação de um serviço para acidentados do trabalho. Rev. Bras. Enf.; Rio de Janeiro, $28: 65-71,1975$.

\section{REFERENCIAS BIBLIOGRAFICAS}

1. AMARAL, R.S. - Ambulatório, Rev. Paul. Hosp., São Paulo, 16 (1): 24-28, jan. 1968.

2. ARANHA, W. - Emergência e urgência. Rev. Paul. Hosp., São Paùo, 17 (13): 27-27, mar. 1969.

3. BRASIL, Leis, decretos, etc., Lei n. ${ }^{\circ}$ 5.316, de 14 de setembro de 1967. Dispõem sobre Seguros de Acidentados do Trabalho.

4. BRASIL, Leis, decretos, etc. Dec. n. ${ }^{\circ}$ 61.784, de 28 de novembro de 1967. Regulamenta a Lei sobre Seguros de Acidentes do Trabalho (5316/ 67).

5. FACULDADE DE HIGIENE E SAÚDE PÚBLICA DA UNIVERSIDADE DE SÃO PAULO. Temas de Administração Hospitalar. Cadeira de Administração Hospitalar. (apostila mimeografada) maio, 1969.

6. GONChALVES, E.L. at al - Programa de dimensionamento de um ambulatório. Rev. Paul. Hosp, São Paulo, 20 (6): 27-33, jun. 1972.

7. INSTITUTO NACIONAL DE PREVIDENCIA SOCIAL - Catálogo de Material Permanente SP. (livreto mimeografado) Assessoria de Enfermagem da Coordenação de Assistência Médica em São Paulo, 1969.

8. INSTITUTO NACIONAL DE PREVIDENCIA SOCIAL - Coordenação de Seguros Sociais, Circular n. ${ }^{\circ}$ 307, de 20 de fevereiro de 1974 Dispõem sobre "Normas de Credenciamento para Atendimento de Acidentados do Trabalho".
9. INSTITUTO NACIONAL DE PREVIDENCIA SOCIAL - Coordenação de Seguros Sociais, Circular n. ${ }^{\circ}$ 191, de 24 de janeiro de 1974. Dispõem sobre "Vistoria de Ambulatório-Pronto-Socorro dos Hospitais para prestação de assistência médica a acidentados do trabalho".

10. INSTITUTO NACIONAL DA PREVIDE'NCIA SOCIAL - Secretaria de Seguros Sociais. Memo-Circular n. ${ }^{\circ} 105$ de 16 de março de $15 \cdot 72$. Dispõem sobre condições para atendimento fisioterápico de acidentados do trabalho.

11. LIFTON, J.G. - "Eight Wayz to Provide physician covenage of the emergency room and how to tell wich is best". Moderno Hospital, 79-82, oct., 1973.

12. MEZZONO, A.A. - Unidade de Emergência num hospital de 200 leitos. Rev. Paul. Hosp., São Paulo, 17 (1) : 38-44, jan. 1969.

13. MINISTERIO DA SAÚDE. Programas mínimos funcionais. Unidade de Ambulatório. Fascículo NH-4.7.

14. ORGANIZAÇAO MUNDIAL DE SAƯDE - Publicações Científicas n. ${ }^{\circ}$ 91. Atendimento de Acidentados do Trabalho. 1969.

15. STEFANO, I.J. - Estudo para um Serviço de Fisioterapia num hospital de 500 leitos. Rev. Paul. Hosp., São Paulo, 17 (3): 30-36, mar. 1969.

16. VOROBOW, Gricha - Serviço de Emergência $\mathbf{X}$ Ambulatório. Rev. Paul. Hosp., São Paulo, 20 (5): 30-32, mai., 1972. 